REVIEW OF METHODS APPLICABLE

TO THE CALCULATION OF GAP CONDUCTANCE IN ZIRCALOY-CLAD UO ${ }_{2}$ FUEL RODS

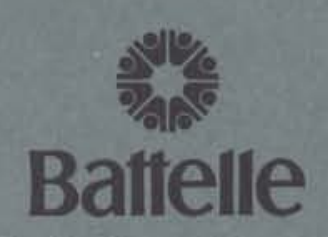

Pacific Northwest Laboratories

Richland, Washington 99352

\title{
APRIL 1975
}

Prepared for the U.S. Atomic Energy

Commission under Contract AT(45-1):1830 
NOTICE

This report was prepared as an account of work sponsored by the United States Government. Neither the United States nor the United States Atomic Energy Commission, nor any of their employees, nor any of their contractors, subcontractors, or thier employees, makes any warranty, express or implied, or assumes any legal liability or responsibility for the accuracy, completeness or usefulness of any information, apparatus, product or process disclosed, or represents that its use would not infringe privately owned rights.

\author{
PACIFIC NORTHWEST LABORATORY \\ operated by \\ BATTELLE \\ for the \\ U.S. ATOMIC ENERGY COMMISSION \\ Under Contract AT(45-1)-1830
}

\author{
Printed in the United States of America. \\ Available from \\ National Technical Information Service \\ U.S. Department of Commerce \\ 5285 Port Royal Road \\ Springfield, Virginia 22151 \\ Price: Printed Copy 54.00; Microfische 52.25
}


BNWL-1894

UC-78b

REVIEW OF METHODS APPLICABLE TO THE CALCULATION OF

GAP CONDUCTANCE IN ZIRCALOY-CLAD U0, FUEL RODS

by

D. D. Lanning

C. R. Hann

Apri1 1975

On January 19, 1975, research and development programs of the U.S. Atomic Energy Commission (AEC) became part of the newly formed Energy Research and Development Administration (ERDA). In this report, since it refers to work done in 1974, most references are to AEC programs.

BATTELLE

PACIFIC NORTHWEST LABORATORIES

RICHLAND, WASHINGTON 99352 


\section{CONTENTS}

LIST OF FIGURES

LIST OF TABLES

INTRODUCTION

PART I - HEAT CONDUCTION THROUGH THE INTERFACIAL GAS $\cdot$. $\cdot$. 2

Introduction of Terms and Concepts . . . . . . . . . 2

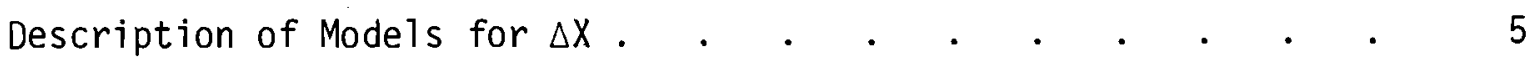

Methods for Calculating the Temperature Jump Distance . . . 7

Results of Linear Regression on Ross-Stoute Data . . . . . . 9

PART I I - HEAT CONDUCTANCE THROUGH CONTACT POINTS . . . . . 13

Basic Terms and Concepts. . . . . . . . . . . 13

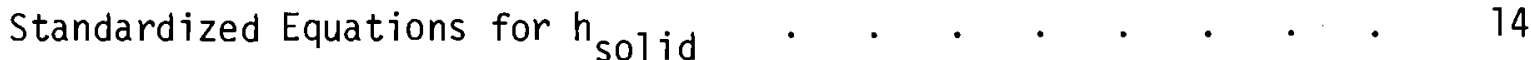

Numerical Comparisons of Equations for $h_{\text {solid }} \cdot \cdot \cdot \cdot \cdot \cdot \cdot 16$

PART III - CONCLUSIONS AND RECOMMENDATIONS FOR GAPCON-THERMAL-2 • • 20

Calculation of the Temperature Jump Distance G . . • . . 20

Calculation of Effective Gap Width, $\Delta X$. . . . . . . 21

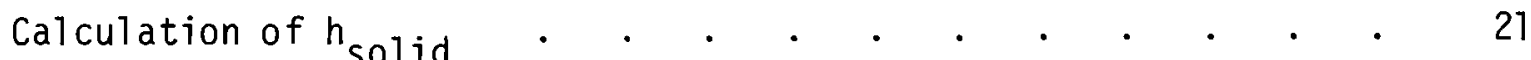

REFERENCES

APPENDIX A: Definitions and Units for Symbols Used in Equations. . A.1

APPENDIX B: Derivation of Standardized Equations for

Temperature Jump Distance . . . . . . . . B.1

APPENDIX C: Derivation of Standardized Equations

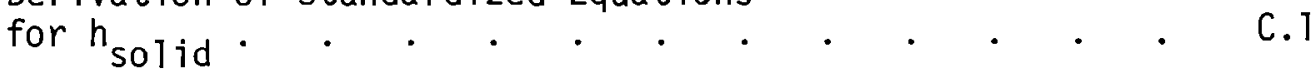




\section{LIST OF FIGURES}

1 Temperature Drop Across the Fue1-Clad Gap

2 Temperature Jump Distance for Xe-He Mixtures at $260^{\circ} \mathrm{C}$ and $1 \mathrm{~atm}$. Pressure

3 Ross-Stoute Data for $\Delta x$ Versus Calculated Values from the GAPCON Model

4 Comparison of Models for Solid-Solid Conductance

5 Data for $\mathrm{R}_{1}$ and $\mathrm{L}_{1}$ for $\mathrm{UO}_{2}$

\section{LIST OF TABLES}

1 Equations for Temperature Jump Distance*

2 Results of Regression on Ross-Stoute Data

3 Equations for $h_{\text {solid }}$

4 Experimental Conditions for $h_{\text {solid }}$ Data

5 Input for Numerical Comparisons

6 Calculated Results for $h_{\text {sol id }}\left(W / \mathrm{cm}^{2}-{ }^{\circ} \mathrm{C}\right)$ 
REVIEW OF METHODS APPLICABLE TO THE CALCULATION OF

GAP CONDUCTANCE IN ZIRCALOY-CLAD UO 2 FUEL RODS

\section{$\underline{\text { INTRODUCTION }}$}

The program GAPCON-THERMAL-1 solves for the steady-state temperature distribution in a reactor fuel rod by iterating on converging choices for the gap conductance. This conductance is calculated via a modification of the Ross-Stoute model. $(1,2)$ In a continuing effort to update and improve the program, a review was made of data and calculational methods (in addition to those of Ross and Stoute) which are applicable to gap conductance. Our concern was to determine if modifications would be needed to use GAPCON-THERMAL- 1 in ranges of temperature, gas pressure, and interfacial gas types not covered by the Ross-Stoute data. Specifically, note the following:

\begin{tabular}{|c|c|c|}
\hline Parameter & $\begin{array}{l}\text { Range of Interest } \\
\text { in Power Reactor } \\
\text { Calculations } \\
\end{array}$ & $\begin{array}{c}\text { Range of } \\
\text { Ross-Stoute Data } \\
\end{array}$ \\
\hline $\begin{array}{l}\text { Mean } \\
\text { Temperature } \\
\text { in Gap }\end{array}$ & $300-1000^{\circ} \mathrm{C}$ & $200-360^{\circ} \mathrm{C}$ \\
\hline $\begin{array}{l}\text { Fill Gas } \\
\text { Pressure }\end{array}$ & $2-300 \mathrm{~atm}$ (abs.) & $0.5-1 \mathrm{~atm}$ (abs.) \\
\hline $\begin{array}{l}\text { Contact } \\
\text { Pressure }\end{array}$ & $0-3000$ psi & $1400-7000$ psi \\
\hline Gas Type & $\begin{array}{l}\text { Mixed } \mathrm{He}, \mathrm{Xe}, \mathrm{Kr} \text {, } \\
\mathrm{H}_{2}, \mathrm{~N}_{2} \text {, and } \mathrm{CO}_{2}\end{array}$ & $\frac{\text { Pure }}{X e} \mathrm{He}, \mathrm{Ar}, \mathrm{Kr}$, \\
\hline
\end{tabular}

When fuel is not contacting the cladding the thermal conduction is primarily through the gas. When fuel does contact the cladding, $5-20 \%$ of the heat may flow through the contact points, depending on the contact pressure, the gas mix in the gap, and the surface profiles. In no practical case however, does heat flow due to radiation exceed $22 \%$ of the total. Therefore, our review is 1 imited to conduction through the gas and through 
the contact points. This report summarizes the results of that review and presents our recommendations for modification of the GAPCON program.

The first two sections of this report present, discuss, and numerically compare various approaches to calculating the conductance through the gas ( $\left.h_{\text {gas }}\right)$, and the conductance through contact points ( $h_{\text {solid }}$ ), respectively. Conclusions and recommendations for the GAPCON program are presented in the third section, page 20. The symbols and metric engineering units used throughout are listed in Appendix A. The equations for temperature jump distance and for $h_{\text {sol }}$ id are put into standardized formats and units in Appendices $B$ and $C$, respectively.

\section{PART I - HEAT CONDUCTION THROUGH THE INTERFACIAL GAS}

\section{I.A. INTRODUCTION OF TERMS AND CONCEPTS}

As indicated in Figure 1, the temperature drop across the fuel-clad gap due to conduction through the gas can be represented by two components:

1) The temperature drop through the bulk of the gas, which depends upon the gas conductivity, $K$, according to the Fourier equation,

$$
-K \frac{d T}{d x}=\text { surface heat flux (S.H.F.) }
$$

(For $K$ constant, this temperature drop is linear in $x$. )

2) A temperature drop at each surface which arises from imperfect energy exchange between the gas and the surface. This drop is called the "temperature jump."

These two components are combined into one equation by extrapolating the linear fall of temperature through the gas to incorporate the true temperature at the surfaces. The length of this extrapolation is called the "temperature jump distance," $\mathrm{g}$.

The Fourier conditions can then be integrated to form

$$
\frac{K \Delta T}{\Delta X}=S . H . F .
$$




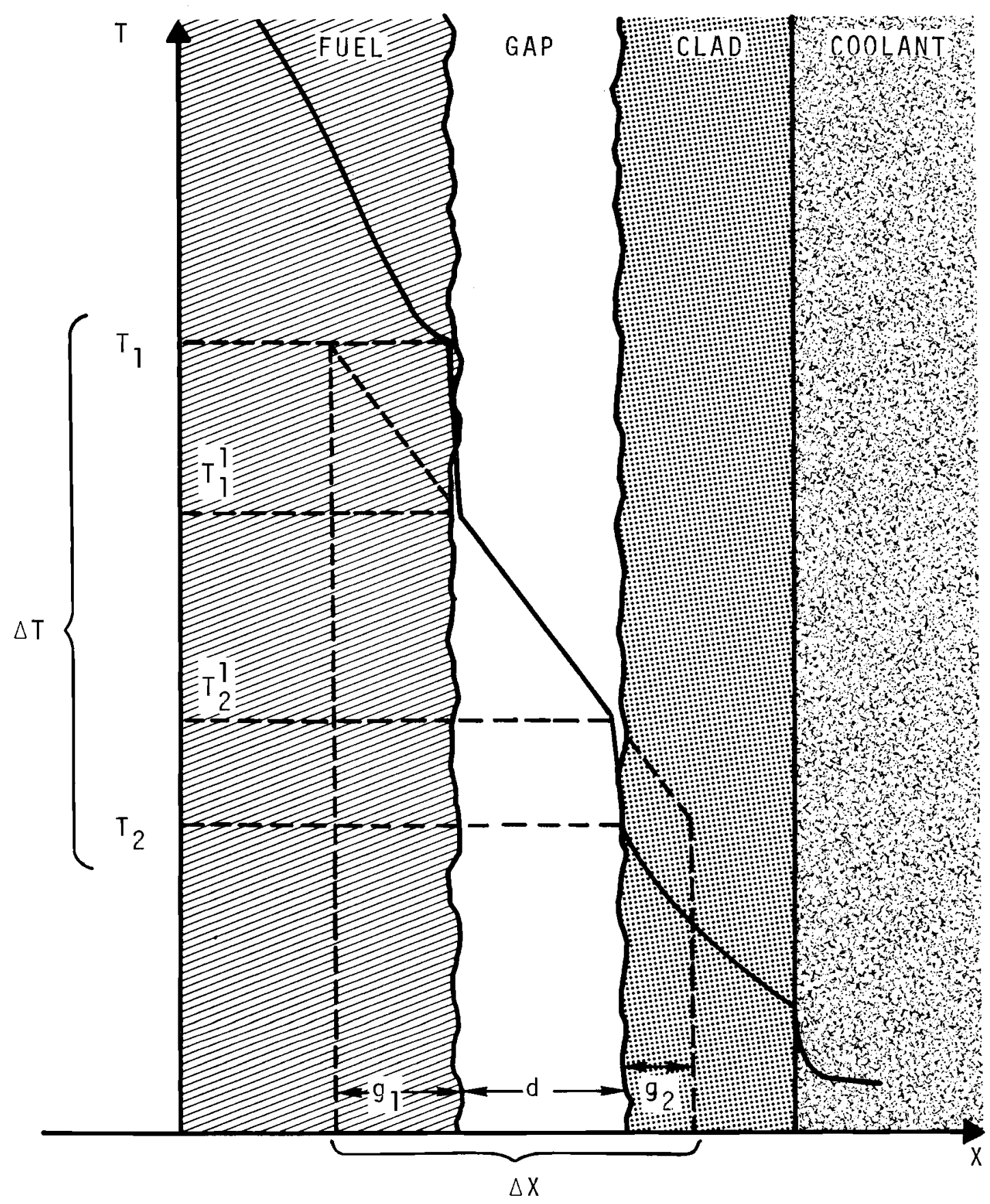

FIGURE 1. Temperature Drop Across the Fuel-Clad Gap (Jump distances are exaggerated) 
where

$$
\begin{aligned}
& \Delta T=T_{1}-T_{2}=\text { fuel surface temperature - clad inner temperature. } \\
& \Delta X=d+g_{1}+g_{2}=\text { physical gap size }+ \text { temperature jump distance. }
\end{aligned}
$$

The defining equation for $h_{\text {Tot. }}$ is $h_{\text {Tot. }}=\frac{\text { S.H.F. }}{\Delta T}$

Combining, we have

$$
h_{\text {Tot. }}=h_{\text {gas }}=\frac{k_{\text {gas }}}{d+g_{1}+g_{2}}
$$

Now, $g_{1}+g_{2}$ is estimated to be on the same order as the mean free path of the fill gas, which in typical power reactor situations is on the order of the surface roughness of the fuel $\left(5 \times 10^{-5}-2 \times 10^{-4} \mathrm{~cm}\right)$. Thus, for operating gaps of $10^{-3} \mathrm{~cm}$ or greater, $h_{\text {gas }}$ can be approximated simply as

$$
h_{\text {gas }}=\frac{k_{\text {gas }}}{d}
$$

where $d$ is the nominal gap size.

However, as fuel and clad approach contact, several complications arise: the temperature jump distance must be accounted for, and the effective distance between the surfaces, $d_{\text {eff. }}$ is some complicated function of the actual surface profiles of fuel and clad; in addition there is some conductance through the contact points, so that $h_{\text {Tot. }}=h_{\text {gas }}+h_{\text {solid }}$.

One way to circumvent these difficulties would be to define the "total effective distance," $\Delta x_{\text {eff. }}$, of the gap to be

$$
\Delta x_{\text {eff. }}=d_{\text {eff. }}+g_{1}+g_{2}=k_{\text {gas }} / h_{\text {gas }}
$$

and then determine $\mathrm{k}_{\text {gas }} / \mathrm{h}_{\text {gas }}$ * at sufficient points to span the ranges of interest of surface temperatures, surface conditions, gas temperatures and * Note that $h_{\text {gas }}$ is not measureable directly for surfaces in contact. The
measureable quantities, S.H.F. and $\Delta T$, yield $h_{T}$. In the Ross-Stoute experiments, the conductance was measured in vacuo, then gas introduced with the surfaces held in contact, and the conductance remeasured. The difference of the two measurements was called "h gas." 
pressures, and gas mixes. This simply has not been done. Referral to the ranges of interest in the Introduction gives an indication of the difficulty and expense of such a project.

In the absence of sufficient data for $\Delta x$, one must estimate $d_{\text {eff. }}$ and $g_{1}+g_{2}$ by theory and models which do account for the available data and extrapolate conservatively into the unknown regions. It should be kept in mind that no model will be theoretically "exact" because the estimation of

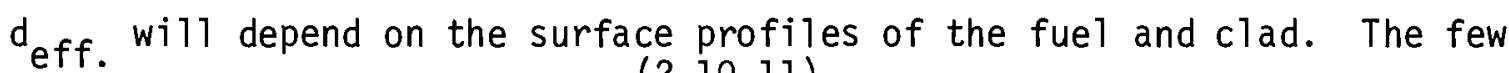
published profile measurements $(2,10,11)$ demonstrate that $d_{\text {eff. }}$ cannot be characterized with any exactitude. It is also clear that the surface profiles will change due to fuel cracking, plastic clad strain, and deformation of contact points.

Two distinct models were considered for $\Delta X$ : that used by Shlykov (3) and the more familiar one used by Kennard, ${ }^{(4)}$ Cetinkale and Fishenden (5) and many later authors including Ross and Stoute. (This latter model is referred to as the "standard" model.) Three distinct ways of calculating temperature jump distance were considered: Kennard's classical approach, ${ }^{(4)}$ GAPCON's ${ }^{(1)}$ present simplified approach, and an approach by Lloyd ${ }^{(6)}$ derived from transport theory. Combining the two models for $\Delta \mathrm{X}$ with each of the three calculations of $g_{1}+g_{2}$ yields six different approaches to calculate $\Delta X$. These various models and methods are described and compared in Sections I. B and C. In Section I.D. are presented the results of 1 inear regression of a11 6 different approaches for calculating $\Delta X$, as applied to the Ross and Stoute data.

\section{I.B. DESCRIPTION OF MODELS FOR $\triangle X$}

1) The "standard" model (as presently used in GAPCON-THERMAL-1) The "standard" model is simply the extension of Figure 1 to the contact situation:

$$
\Delta x_{\text {eff. }}=d_{\text {eff. }}+g_{1}+g_{2}
$$


where $d_{\text {eff. }}$ is some effective value for the physical separation of the surfaces due to their roughness.

It might be expected that $d_{\text {eff. }}$ would be a function of the interfacial pressure as well as surface roughness. Cetinkale and Fishenden ${ }^{(5)}$ did not find such a dependence during measurement of conductance through metalmetal pairs at pressures up to $800 \mathrm{psi}$. Their measurements indicated

$$
d_{\text {eff. }}=0.61\left(R_{1}+R_{2}\right)
$$

(where $R_{1}$ and $R_{2}$ are roughnesses of surface 1 and 2 , respectively.)

The Ross and Stoute data seems to indicate a slight dependence on pressure for $\mathrm{UO}_{2}-\mathrm{Zr}$ pairs in the pressure range of 1400 to 7000 psi and a fit of their data indicates

$$
\begin{aligned}
d_{\text {eff. }} & =C\left(R_{1}+R_{2}\right) \\
\text { where } c & =2 \exp \left[-1.25 \times 10^{-3} P_{a}\right],
\end{aligned}
$$

$P_{a}$ is interfacial pressure in $\mathrm{kgf} / \mathrm{cm}^{2}$.

In the standard model $d_{\text {eff }}=C\left(R_{1}+R_{2}\right)$ with $C$ defined as above. The factor 2 is an attempt to incorporate the effect of "waviness" of the surface and distribution of peak heights on the conductance. $(3,10)$ The exponential term seeks to model the reduction of these effects with increasing contact pressure.

\section{2) The Shlykov Model}

An empirical version of the standard model comes from the Russian literature on contact conductance. Shlykov demonstrated excellent correlation of several hundred data points for metal-metal pairs in air and other gases from the following considerations: 
The mathematical definition of $\Delta x_{e f f}$ is

$$
\frac{1}{\Delta X_{\text {eff. }}}=\frac{1}{S} \int_{\substack{\text { Surface of } \\ \text { interest }}}^{d S /\left[d(\vec{r})+g_{1}+g_{2}\right]}
$$

where $d \overrightarrow{(r)}$ is the physical separation of the surfaces at position $\vec{r}$. If one defines $V$ as $\Delta x_{\text {max }} /\left(g_{1}+g_{2}\right)$ and $y$ as $\Delta x_{\max } / \Delta x_{\text {eff. }}$, then the above definition can be rewritten as

$$
Y=\int_{0}^{1} d A /(e+1 / V)
$$

where $A$ is the relative area of true contact and $e$ is $d(\vec{r}) / \Delta x_{\max }$, the relative gap height.

From examining surface profiles of typically machined surfaces, Shvets and Dyban ${ }^{(7)}$ developed a correlation for $Y$ as a function of $V$. This socalled "bearing-surface curve" is

$$
Y=3.33+\frac{10}{V}+\frac{4}{v^{2}}-4\left(\frac{1}{v^{3}}+\frac{3}{v^{2}}+\frac{2}{V}\right) \ln (1+v)
$$

Shlykov used this correlation, coupled with his estimate that $\Delta \mathrm{X}_{\max }=$ $2\left(R_{1}+R_{2}\right)$, to correlate the metal-metal contact conductance data. To summarize, his calculation of $\Delta x_{e f f}$. proceeds as follows:

a) Calculate $V=2\left(R_{1}+R_{2}\right) /\left(g_{1}+g_{2}\right)$

b) Calculate $Y$ from $V$ by the bearing-surface curve

c) Calculate $\Delta x_{\text {eff. }}=2\left(R_{1}+R_{2}\right) / Y$

\section{I.C. METHODS FOR CALCULATING THE TEMPERATURE JUMP DISTANCE}

Tabulated below are the three methods for calculating temperature jump distance, $g$, mentioned earlier. The methods have been put in a standardized format, that is, 


$$
g=A\left[\frac{K_{\text {gas }} \sqrt{T_{\text {gas }}}}{P}\right] F\left(a_{i}, f_{i}, M_{i}\right)
$$

where $g$ is in $\mathrm{cm}$., $A$ is a constant, and $F$ is a function of thermal accommodation coefficients $a_{i}$, mole fractions $f_{i}$, and molecular weights $M_{j}$ of the components of the gas. Please refer to Appendix $A$ for a complete definition of symbols and units, and to Appendix $B$ for deriviation of the forms presented here.

TABLE 1. Equations for Temperature Jump Distance*

The

Constant A

(for $g$,

Method

in $\mathrm{cm}$. )

The Function $F$ for Mixed Gases

The Function $F$

for Pure Gases

Kennard

$\left(\frac{2-a_{\operatorname{mix}}}{a_{\operatorname{mix}}}\right) \sqrt{\frac{1}{\sum f_{j} / M_{i}}}$

$\left(\frac{2-a}{a}\right) \sqrt{M}$

GAPCON

$$
\left(\frac{\sum_{i} f_{i} M_{j} k_{i} / \sum_{j} \phi_{i j} f_{j}}{\sum_{i} f_{j} k_{i} / \sum_{j} \phi_{i j} f_{j}}\right) \sqrt{\frac{1}{\sum f_{j} M_{i}}}
$$

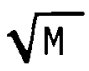

25220 .

$$
\frac{1}{\sum a_{i} f_{i} / \sqrt{M_{i}}}
$$

$\frac{\sqrt{M}}{a}$

One can see that the methods are rather similar for pure (monatomic) gases, but differ considerably for mixed gases. ${ }^{\star \star}$ Notice also the methods

* In the above equations "a" is the thermal accommodation coefficient for the gas on a given surface. As discussed in Appendix $B$, we prefer recent measurements by U11man et a1. (8) for estimating "a." These measurements show "a" to be dependent on the temperature of the surface, so that $g_{1}$ and $g_{2}$ should in general be calculated separately and not considered equal. It is true, however, that $g_{1}+g_{2} \approx 2\left[g\left(T_{\text {avg. }}\right)\right]$, where $T_{a v g .}=\left(T_{1}+T_{2}\right) / 2$.

** The equations in Table 2 are derived for pure and mixed monatomic gases only. Introducing more complicated gases complicates the derivation beyond the scope of this simple comparative study. 
vary in the amount of input information required preliminary to the calculation of $\mathrm{g}$. The Kennard approach requires an estimate of " $\mathrm{a}_{\text {mix }}$ " for mixed gases in addition to $a_{j}$ for pure cases. As U11man notes, $(8)$ only Godesar has put forth an explicit method for deducing $a_{\operatorname{mix}}$ from $a_{j}$, and no basis is provided for that method. The lloyd method requires an estimate of "a" for each of the components individually, but not for the mix as a whole; and the GAPCON-THERMAL model requires no estimate of "a" whatsoever. Because the U11man data and that compiled by Trilling(14) indicate that "a" is dependent on the species of gas and the temperature of the surfaces, we question whether the present GAPCON equation is theoretically sound, even though it may account for presently available (and highly scattered) data for $\Delta X$, as will be seen in section I.D.

To make the difference in the equations more graphic, they were each used to calculate the temperature jump distance for He-Xe mixtures at $1 \mathrm{~atm}$. and $260^{\circ} \mathrm{C}$ (the approximate conditions of the Ross-Stoute measurements). We used the Ullman data for $\mathrm{a}_{\mathrm{He}}$ and $\mathrm{a}_{\mathrm{Xe}}$ (see Appendix B) and estimated "amix ${ }_{\text {mix }}$ by linear interpolation between the two. The results are presented in Figure 2.

\section{I.D. RESULTS OF LINEAR REGRESSION ON ROSS-STOUTE DATA}

One way to evaluate the various possibilities of calculating $\Delta X$ is to fit them to measurements of $\Delta X$ such as the Ross-Stoute data. Figure 3 presents the Ross-Stoute data for $\triangle X$ as compared to the calculated values from the GAPCON model. The purpose of Figure 3 is two fold: to display the data for reference, and to show what linear regression of a model on this data involves. A linear regression code sets the measured values of $\Delta X$ equal to " $Y$ " and the calculated values equal to " $X$ " and finds the least squares estimate for the line "Y" = A "X" $+B$. The least squares estimate of $\Delta X$ would then be

$$
\Delta X_{\text {regression }}=A \Delta X_{\text {calc. }}+B \text {. }
$$




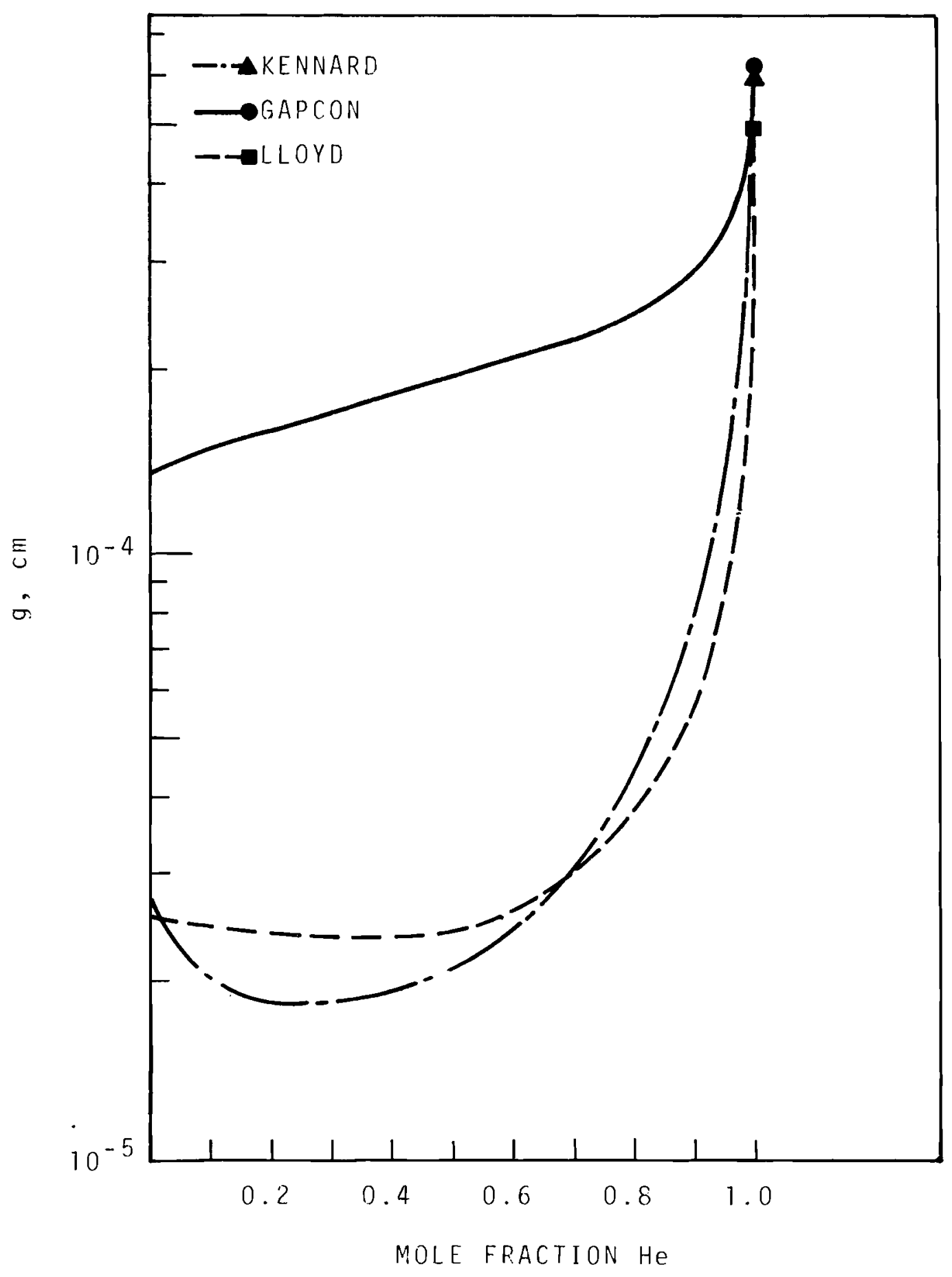

FIGURE 2. Temperature Jump Distance for Xe-He Mixtures at $260^{\circ} \mathrm{C}$ and $1 \mathrm{~atm}$. Pressure 


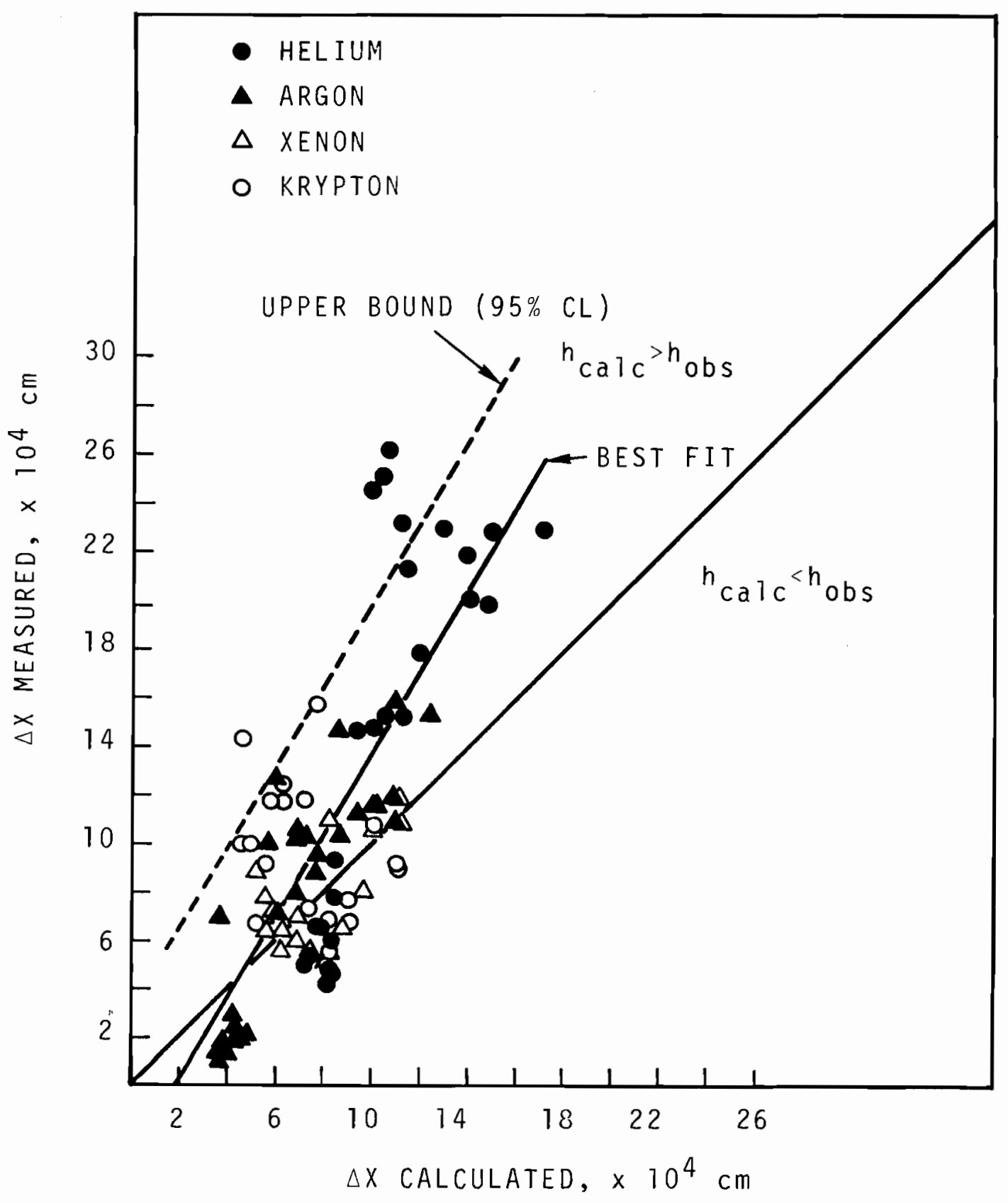

FIGURE 3. Ross-Stoute Data for $\triangle X$ Versus

Calculated Values from the GAPCON Model 
If the model from which $\Delta x_{\text {calc. }}$ is calculated fits the data ideally, the slope, $A$, would be close to 1.0 , the intercept, $B$, would be relatively small, and the correlation coefficient, $\rho$, would be close to 1.0 and the residual standard deviation, $\sigma$, would be relatively small. Thus, $A$ and $B$ are measures of how much the model must be adjusted to fit the data in the least squares sense, and $\rho$ and $\sigma$ are measures of how good the fit is. In Figure 3, the 1ine of 1-1 correspondence is drawn for regression of the GAPCON model on the Ross-Stoute data $(A=1.0, B=0.0)$. Also shown is the line of best fit $\left(A=1.7, B=-3.3 \times 10^{-4} \mathrm{~cm}\right)$ and the $95 \%$ upper bound on that line.

Table 2 summarizes the results of linear regression listed on the RossStoute data for all 6 possible combinations of model and $\mathrm{g}$ calculations.

\section{TABLE 2. Results of Regression on Ross-Stoute Data}

\begin{tabular}{|c|c|c|c|c|c|}
\hline Model & $\begin{array}{l}\text { Method for } \\
\text { Calc. g }\end{array}$ & Slope & $\begin{array}{l}\text { Intercept. } \\
\times 10^{-4} \mathrm{~cm} \\
\end{array}$ & $\begin{array}{l}\text { Corr. } \\
\text { Coef. }\end{array}$ & $\begin{array}{c}\text { Res. Std. Dev } \\
\times 10^{-4} \mathrm{~cm} \\
\end{array}$ \\
\hline \multirow[t]{3}{*}{ Shlykov } & GAPCON & 2.0 & 2.4 & 0.74 & 4.3 \\
\hline & Kennard & 1.5 & +1.4 & 0.71 & 4.5 \\
\hline & Lloyd & 2.5 & -1.0 & 0.76 & 4.1 \\
\hline \multirow[t]{3}{*}{ "Standard" } & GAPCON & 1.7 & -3.3 & 0.77 & 4.1 \\
\hline & Kennard & 1.5 & -1.1 & 0.78 & 4.0 \\
\hline & Lloyd & 1.8 & -1.2 & 0.75 & 4.2 \\
\hline
\end{tabular}

The above results, while not very conclusive, are interesting. The structure of the data (slope of best fit line) is dominated by helium and argon points, for which $g_{1}+g_{2}$ is a significant fraction of $\Delta x$, yet all six methods for calculating $\Delta x$ demonstrate similar regression results! Two conclusions can perhaps be drawn at this point.

1) The Shlykov model appears to be as applicable to the Ross-Stoute data as the standard model. (This may be the first comparison of this model to nonmetallic interfaces.) 
2) The differences in the models for $g_{1}+g_{2}$ do not significantly affect the outcome of $\Delta X$ calculations for typically rough interfaces, and these calculations appear qualitatively correct.

\section{PART II - HEAT CONDUCTANCE THROUGH CONTACT POINTS}

\section{II.A. BASIC TERMS AND CONCEPTS}

In addition to heat flow through the interfacial gas, there is some heat flow through points of contact. Measurements of this conductance for $\mathrm{UO}_{2}$ on metal have been made in vacuo by Rapier et al., (10) and by Ross and Stoute, and in argon by Dean. (13) Measurements for metal-metal pairs have been made and/or correlated by Cetinkale and Fishenden, ${ }^{(5)}$ Fenech and Rohsenow, $(11)$ and Shlykov, ${ }^{(3)}$ among others. Todreus $(12)$ reexamined $\mathrm{UO}_{2}$ metal data in the light of the Mikic model. (15)

All seven above-mentioned references have put forth models which attempt to correlate general or specific measurements of surface profiles plus apparent contact pressure with their measurements of $h_{\text {solid, the solid-solid }}$ contact conductance. All the models have the same basic form:

$$
h_{\text {solid }}=A K_{m} F\left(L_{i} \text { and/or } R_{j}\right)\left(P_{a} / H\right)^{n}, i=1,2
$$

where $A$ is a constant and

$$
\begin{aligned}
\mathrm{K}_{\mathrm{m}}= & \text { mean conductivity, } 2 \mathrm{~K}_{1} \mathrm{~K}_{2} /\left(\mathrm{K}_{1}+\mathrm{K}_{2}\right) \\
\mathrm{F}= & \text { a function of roughness } \mathrm{R} \text { and "wavelength" } \mathrm{L} \\
& \text { ( } \mathrm{L} \text { is the mean peak-peak distance on a surface) } \\
\mathrm{P}_{\mathrm{a}}= & \text { apparent interfacial pressure } \\
\mathrm{H}= & \text { Meyer hardness of the softer material (chosen for its direct } \\
& \text { connection to the yield strength of a metal under a load on a } \\
& \text { point.) } \\
\mathrm{n}= & \text { an exponent, discussed below. }
\end{aligned}
$$

The exponent " $n$ " is taken generally as 0.5 or 1.0 , depending on whether, as contact pressure increases, the contact points are assumed to remain constant in number (but increase in area) or to remain constant in area 
(but increase in number). The dependence of " $n$ " on these two assumptions can be seen from the following considerations:

The assumption is always made that the actual pressure on a contact point will not exceed the Meyer hardness of the softer material. As pressure increases, the actual area of contact will increase to maintain the equation,

$$
\frac{\text { Actual contact area }}{\text { Apparent contact area }}=\frac{\mathrm{Pa}_{\mathrm{a}}}{\mathrm{H}} \text {. }
$$

Now assume $\mathrm{N}$ equally spaced contact points per unit area. Associated with each point is an equivalent cylinder for heat (axis perpendicular to the interface), with cross-section radius $r_{e}$ determined from $\mathrm{N}^{\prime} r_{e}^{2}=1$. The actual radius of the contact spot, " $r$," is determined from the relation,

$$
\frac{\text { Actual contact area }}{\text { Apparent contact area }}=\frac{P_{a}}{H}=\frac{\pi r^{2}}{\pi r_{e}^{2}}
$$

Now if $\mathrm{N}$ increases with pressure, the ratio $r / r_{e}$ does not change, and the so-called constriction resistance, arising from the constriction of heat flow through the contact points, remains constant. Hence $h_{\text {solid }}$ varies as $N$, which varies as $\left(P_{a} / H\right)^{1.0}$. If $N$ remains constant on the other hand, $r / r_{e}$ increases and the (inversely proportional) constriction resistance decreases, such that $h_{\text {solid }}$ varies as $\left(P_{a} / H\right)^{0.5}$. Refer to the paper by Cetinkale and Fishenden(5) for more complete discussion.

\section{II.B. STANDARDIZED EQUATIONS FOR $h_{\text {sol id }}$}

The models proposed for $h_{\text {solid }}$ by the seven references noted in part II.A were placed in standard format and (metric) units. Please refer to Appendix $C$ for details of the derivations. The standardized equations appear in Table 4, in terms of the format.

$$
h_{\text {solid }}=A K_{m}\left(\frac{P_{a}}{H}\right)^{n} F\left(R_{i} \text { and or } L_{i}\right), i=1,2
$$


TABLE 3. Equations for $h_{\text {solid }}$

Values for $A$

(for $h_{\text {solid }}$ )

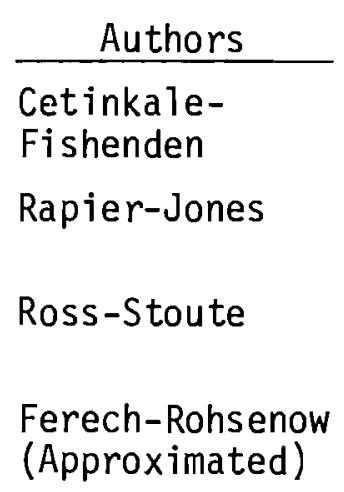

$\frac{\left.\text { in } \mathrm{W} / \mathrm{cm}^{2}-{ }^{\circ} \mathrm{C}\right)}{132.6}$

The Function " $F$ "

Values of

$1 /\left(L_{1}+L_{2}\right)$

1.33

1.0

$1 / L_{1}$

0.5

1.189

$1 /\left(R_{1}^{2}+R_{2}^{2}\right)^{1 / 4}$

1.0

1.89

$\left[1.89\left(R_{1}+R_{2}\right)+\sqrt{\frac{P_{a}}{H}} L_{1}\right]^{-1}$

1.0

Mikic-Todreas

2.314

$R_{1} /\left(R_{1}^{2}+R_{2}^{2}\right)^{1 / 2} L_{1}$

1.0 or

Shlykov

118.9

$Q^{0.86}$

0.5

Dean

$1 /\left(L_{1} L_{2}\right)^{1 / 2}$

0.86

Dean

11.67

The surprising variety of the above models is even more apparent when they are cast in comparable format, as has been done here. This variety probably arises because the models are really just correlations of the data which the various authors developed or chose to examine. These data sets differ considerably in surface condition, pressures and materials involved, as is pointed out in the table below.

TABLE 4. Experimental Conditions for $h_{\text {solid }}$ Data

\begin{tabular}{|c|c|c|c|}
\hline Authors & Materials & $\begin{array}{c}\text { Surface Roughness } \\
\times 10^{-6} \mathrm{~cm} \\
\end{array}$ & $\begin{array}{l}\text { REL. PRESS. } \\
\text { Range, } \mathrm{P}_{a} / \mathrm{H}\end{array}$ \\
\hline $\begin{array}{l}\text { Cetinkale- } \\
\text { Fishenden }\end{array}$ & Various metals & $25-650$ & $>0.2$ \\
\hline Rapier & $\mathrm{UO}_{2}-\mathrm{SS}$ & $9-1600$ & $1.5 \times 10^{-4}$ \\
\hline $\begin{array}{l}\text { Ross- } \\
\text { Stoute }\end{array}$ & $\mathrm{UO}_{2}$-Zirc & $25-400$ & $.01-0.07$ \\
\hline $\begin{array}{l}\text { Fenech- } \\
\text { Rohsenow }\end{array}$ & $\begin{array}{l}\text { Iron- } \\
\text { Aluminum }\end{array}$ & $260-465$ & $0.001-0.08$ \\
\hline $\begin{array}{l}\text { Mikic- } \\
\text { Todreas }\end{array}$ & $\mathrm{UO}_{2}-\mathrm{Zr}, \mathrm{UO}_{2}-\mathrm{SS}$ & $\begin{array}{l}\text { (See Rapier, Dean, } \\
\text { and Ross-Stoute) }\end{array}$ & \\
\hline Shlykov & Various Metals & $1000-2000$ & $<0.03$ \\
\hline Dean & $\mathrm{UO}_{2}$-Zirc & $30-290$ & $0.002-0.006$ \\
\hline
\end{tabular}


II.C. NUMERICAL COMPARISONS OF EQUATIONS FOR $h_{\text {sol id }}$

As can be seen from Table 5 , much of the data for $h_{\text {solid }}$ involves pairs of metals, and is not directly comparable to $\mathrm{UO}_{2}$-metal data. The three references presenting $\mathrm{UO}_{2}$-metal data are so scattered in experimental conditions, and the results so scattered in magnitude, as to make regression analysis difficult to apply.

We therefore picked seven cases spanning the full range of $\left(P_{a} / H\right)$ and roughness values, and applied each of the seven models to each of the cases. The cases are distributed in $\left(\mathrm{P}_{\mathrm{a}} / \mathrm{H}\right)$ and roughness as shown below:

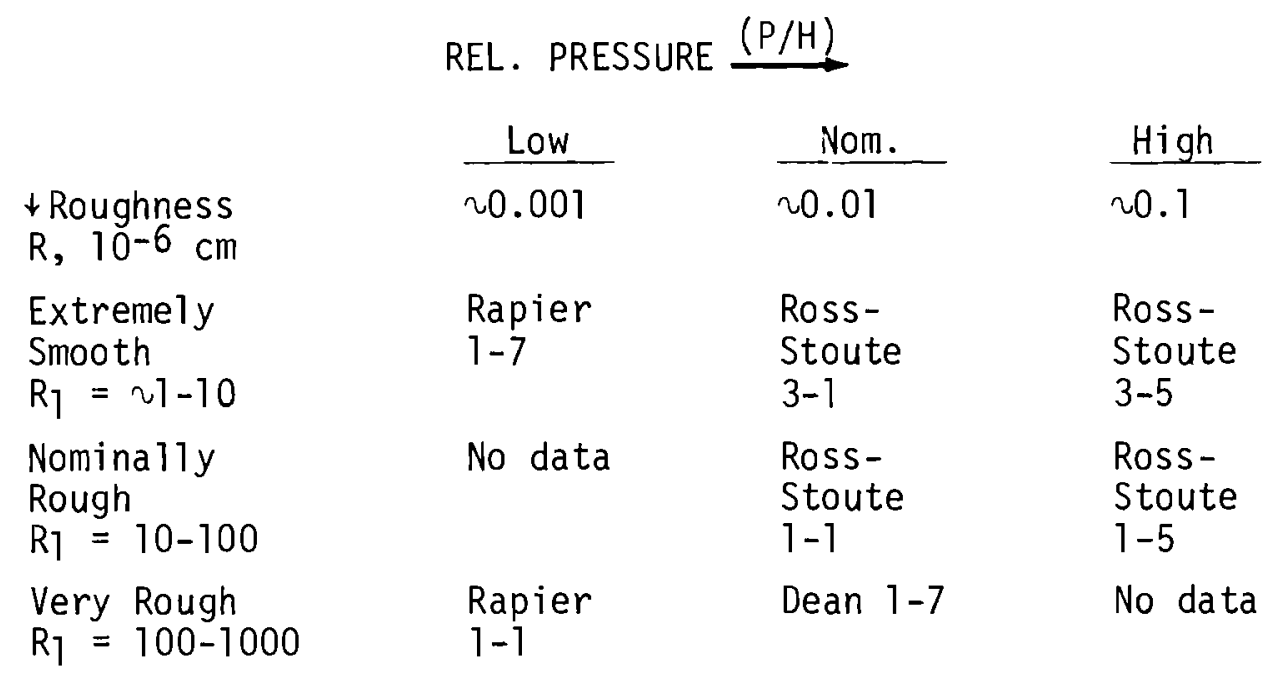

It would be revealing to work examples from each of the 9 cells shown above; but, as noted, data is lacking.

The relevant parameters for each of the seven cases chosen are tabulated as follows (most numbers are taken from the tabulation by Todreas and Jacobs). (12) 
TABLE 5. Input for Numerical Comparisons

\begin{tabular}{|c|c|c|c|c|c|c|}
\hline Case & $\left(\mathrm{P}_{\mathrm{a}} / \mathrm{H}\right)^{\star}$ & $\begin{array}{c}\mathrm{K}_{\mathrm{m}} \\
\mathrm{W} / \mathrm{cm}-{ }^{\circ} \mathrm{C}\end{array}$ & $\mathrm{Cm} \times{ }_{\mathrm{R}}^{\mathrm{R}} \times 10^{-6}$ & $\begin{array}{l}\mathrm{R}_{2} \\
\mathrm{Cm} \times 10^{-6} \\
\end{array}$ & $\begin{array}{l}\mathrm{L}_{1} \\
\mathrm{~cm}\end{array}$ & $\begin{array}{l}\mathrm{L} 2 \\
\mathrm{~cm}\end{array}$ \\
\hline Rapier 1-1 & 0.00015 & 0.112 & 1370 & 940 & 0.015 & 0.0079 \\
\hline Rapier 1-7 & 0.00015 & 0.112 & 16 & 6 & 0.0018 & 0.00099 \\
\hline R\&S $1-1$ & 0.014 & 0.078 & 100 & 48 & $0.0045^{\star \star}$ & $0.0032 \star \star \star$ \\
\hline$R \& S \quad 1-5$ & 0.071 & 0.078 & 100 & 48 & $0.0045^{\star \star}$ & $0.0032^{\star \star}$ \\
\hline R\&S $3-1$ & 0.014 & 0.078 & 24 & 18 & $0.0033^{* *}$ & $0.0025^{\star *}$ \\
\hline R\&S 3-5 & 0.071 & 0.078 & 24 & 18 & $0.0033^{* *}$ & $0.0025 * \star$ \\
\hline Dean 1-7 & 0.005 & 0.078 & 290 & 120 & 0.061 & $0.0032 * \star$ \\
\hline
\end{tabular}

* Nominal H-values were chosen: 600,000 psi for Rapier cases

100,000 psi for Dean and R\&S cases

** L-values are assumed, not measured; could be in error by a factor of 2 .

Values for $h_{\text {solid }}$ were calculated for these cases via all seven models, and the results are tabulated below. The experimental results are listed in the last column for reference.

TABLE 6 Calculated Results for $h_{\text {solid }}\left(W / \mathrm{cm}^{2}-{ }^{\circ} \mathrm{C}\right)$

Cetinkale- Rapier- Ross- Fenech- Mikic-

$\frac{\text { Case }}{\text { Rapier }} \frac{\text { Fishenden }}{0.0053^{*}} \frac{\text { Jones }}{0.091} \frac{\text { Stoute* }}{0.0006} \frac{\text { Rohsenow }}{0.0068} \frac{\text { Todreas }}{0.23^{\star \star}} \frac{\text { Shlykov }}{0.00045} \frac{\text { Dean }}{0.018} \frac{\text { mental }}{0.08}$

$1-1$

$\begin{array}{lllllllll}\text { Rapier } & 0.045 & 0.80 & 0.0050 & 0.50 & 1.6 & 0.021 & 0.15 & 0.42\end{array}$

$\begin{array}{lllllllll}\text { R\&S } & 4.8 & 2.0 & 0.14 & 2.6 & 0.51 & 0.15 & 3.5 & 0.12\end{array}$

$1-1$

$\begin{array}{lllllllll}\text { R\&S } & 40.3 & 4.6 & 0.64 & 6.8 & 2.6 & 0.62 & 17.0 & 0.70\end{array}$

$1-5$

R\&S

3-1

R\&S

3-5

Dean

$1-7$

6.0

2.8

0.21

4.3

0.61

3.1

4.4

0.032

52.4

$\begin{array}{lll}6.3 & 1.0 & 11.0\end{array}$

3.1

12.3

$23.0 \quad 1.0$

* Assuming $A_{0}=1.0 \mathrm{~cm}^{1 / 2}$

** In these cases the Zircaloy is the "controlling surface." 
If the Todreas-Mikic values are reduced by a factor of 4 , they come into rather good agreement overall with the experimental values, granted the uncertainty in $L_{i}$ for the Ross-Stoute data. For no other model considered can such a simple change effect such good overall agreement among these cases.

Another way to compare these models is to plot $h_{\text {solid }}$ (calculated) as a function of $\mathrm{P}_{\mathrm{a}} / \mathrm{H}$ for some nominal values of roughness and $\mathrm{K}_{\mathrm{m}}$. This has been done in Figure 4 for models of Dean, Ross and Rapier, and Mikic and Shlykov for reference. Also included on Figure 4 are qualitative estimates of the ranges of Dean Rapier and Ross-Stoute data, (shaded areas) normalized to the nominal conditions indicated. Such a normalization is of course somewhat qualitative, but the major trends are clear:

1) Each author's model correlates his own data well but does not extrapolate to include the data from each of the other two.

2) The Dean data is relatively high. (This may be due to the relatively high values they report for $L_{7} / R_{7}$, which may not be typical of the other two sets.) *

3) The Mikic-Todreas model (modified by a factor of $1 / 4$ ) is conservative with respect to all the data sets.

Figure 5 presents a plot of the ratio $L_{1} / R_{1}$ for the measured values reported by Rapier and by Dean. Since this ratio is not controlled in the production and operation of reactor fuel (and since $h_{\text {solid }}$ may be inversely proportional to it, according to the Mikic model.), we think it best to remain conservative in the estimation of $h_{\text {solid }}$. We thus prefer the Mikic model at this point, modified as indicated. We propose to estimate $\mathrm{L}_{1}$ from $R_{1}$ via the correlation of the data points noted on Figure 5.

* The effect of this, according to the Mikic model, is to make the Zircaloy the controling surface, which raises the conductance. In normalizing the Dean data $L_{j} / R_{1}$ values typical of the other two data sets were assumed. 


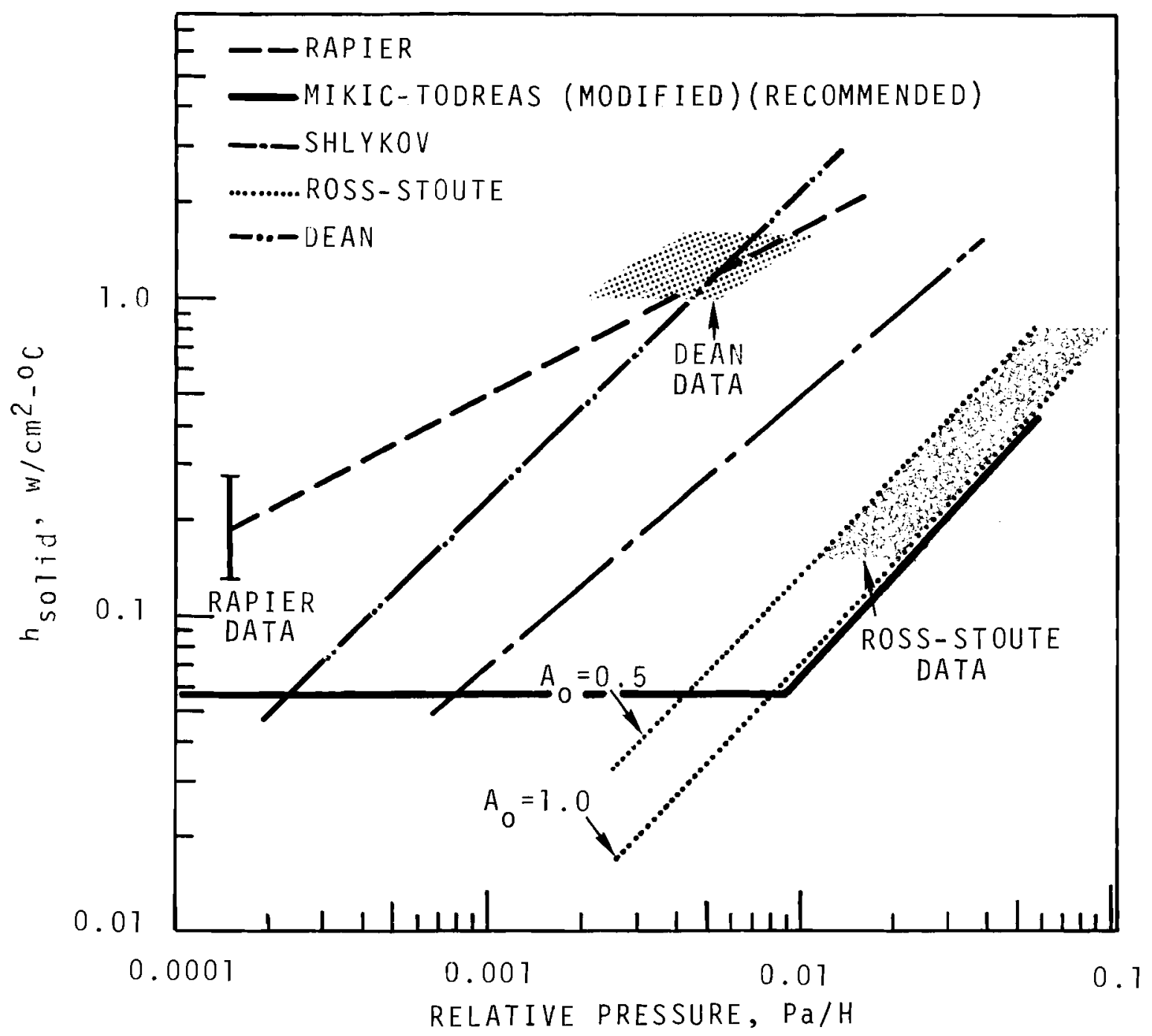

FIGURE 4. Comparison of Models for Solid-Solid Conductance (Data is normalized for

$$
\begin{aligned}
& R_{m}=\sqrt{\frac{R_{1}^{2}+R_{2}^{2}}{2}}=1 \times 10^{-4} \mathrm{~cm} \\
& \left.K_{m}=0.08 \mathrm{~W} / \mathrm{cm}-{ }^{\circ} \mathrm{C}\right)
\end{aligned}
$$




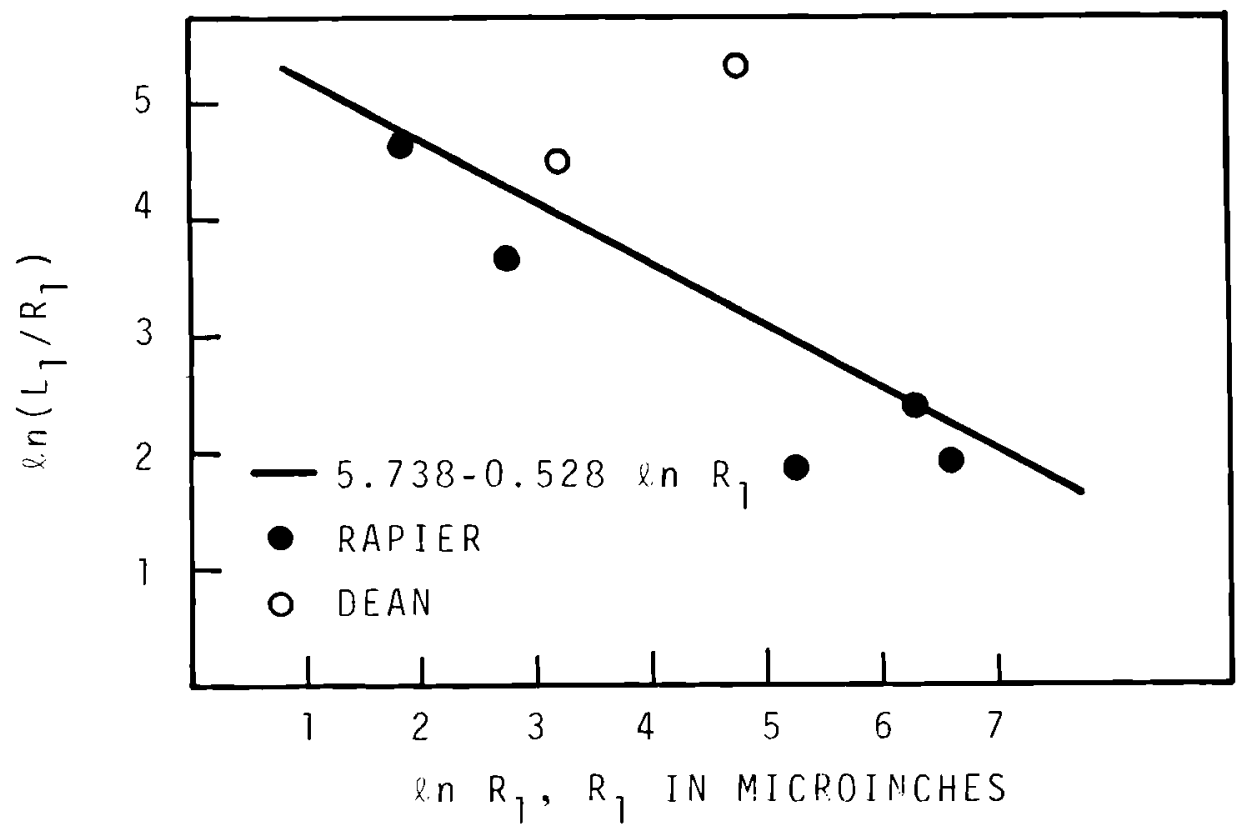

FIGURE 5. Data for $R_{1}$ and $L_{1}$ for $\mathrm{UO}_{2}$

PART III - CONCLUSIONS AND RECOMMENDATIONS FOR GAPCON-THERMAL-2

\section{III.A. CALCULATION OF THE TEMPERATURE JUMP DISTANCE $\mathrm{g}$}

Both Kennard and Lloyd indicate that temperature jump distance should be a function of the accommodation coefficient. Furthermore, U1 Iman has shown that the accommodation coefficient is dependent on the species of gas and the temperature of the surface. All of the models do correlate the Ross-Stoute data significantly. However, only the Lloyd model takes variation of the accommodation coefficient into account. For this reason, and because the Lloyd model is more attractive in the calculation of $\mathrm{g}$ for mixed gases, we chose it as the basic model for the temperature jump distance. 


\section{III.B. CALCULATION OF EFFECTIVE GAP WIDTH, $\triangle X$}

As indicated in Table 3, the use of the Lloyd temperature jump distance with either the standard or Shlykov model leads to nearly identical regression results with the Ross-Stoute data for $\Delta X$. We recommend the use of the standard model, not because it is any more theoretically satisfying but because we encountered convergence problems when the Shlykov model was used in GAPCON-THERMAL. Note that the regression model for input is

$$
\Delta \mathrm{X}_{\text {reg. }}=1.8 \Delta \mathrm{x}_{\text {calc }}-0.00012
$$

where $\Delta x_{\text {calc. }}=C\left(R_{1}+R_{2}\right)+\left(g_{1}+g_{2}\right)_{\text {Lloyd }}$

and

$$
\begin{aligned}
C= & 2 \exp \left(-0.00125 P_{a}\right) \text { as before (here, } P_{a} \text { is in } \mathrm{kgf} / \mathrm{cm}^{2} \\
& \text { and } R_{1}, R_{2} \text { are in cm.) }
\end{aligned}
$$

\section{III.C. CALCULATION OF $h_{\text {solid }}$}

As noted at the end of Part II, the Mikic-Todreas model (reduced by a factor of 4) is conservative compared to available data for $\mathrm{h}_{\text {solid }}$ in $\mathrm{UO}_{2}$ metal pairs. We recommend its use until more data becomes available for $\mathrm{h}_{\text {solid }}$ in as-fabricated and irradiated fuel rod materials. 


\section{REFERENCES}

1. C. R. Hann, C. E. Beyer, and L. J. Parchen, GAPCON-THERMAL-1: A Computer Program for Calculating the Gap Conductance in Oxide Fuel Pins, BNWL-1778, 1973.

2. A. M. Ross, and R. L. Stoute, Heat Transfer Coefficient Between U02 and Zircaloy-2, AECL-1552, 1962.

3. Y. L. Shlykov, "Thermal Contact Resistance," Thermal Engineering 12 , (1966) p. 102.

4. E. H. Kennard, Kinetic Theory of Gases, McGraw-Hi11 New York, 1938, pp. $311-325$.

5. T. N. Cetinkale and M. Fishenden, "Thermal Conductance of Metal Surfaces in Contact," Instn. of Mechanical Engineers, London, 1951.

6. W. R. Lloyd, D. P. Wilkins and P. R. Hill, "Heat Transfer in Multicomponent Monatomic Gases in the Low, Intermediate and High Pressure Regime," (Nuclear Thermionics Conference, 1973).

7. I. L. Shvets and E. P. Dyban, Inzh. Zh., 3, 1964.

8. A. Ullman, R. Acharya and D. R. 01 ander, "Thermal Accommodation Coefficients of Inert Gases on Stainless Steel and $\mathrm{UO}_{2}$," Journal of Nuclear Materials 51,1974 p. 277-279.

9. R. B. Bird, W. F. Stewart, and E. N. Lightfoot, Transport Phenomena, John Wiley \& Sons, New York, 1966.

10. A. C. Rapier, T. M. Jones, and J. E. McIntosh, "The Thermal Conductance of Uranium Dioxide/Stainless Steel Interfaces," International Journal of Heat and Mass Transfer 6, p. 397, 1963.

11. H. Fenech and W. M. Rohsenow, Thermal Conductance of Metallic Surfaces in Contact, NYO $2136,1959$.

12. N. Todreas and G. Jacobs, "Thermal Contact Conductance of Reactor Fuel Elements," Nuclear Science and Engineering 50, p. 283, 1973.

13. R. A. Dean, Thermal Contact Conductance Between $\mathrm{UO}_{2}$ and Zircaloy 2 , CVNA-127, 1962 .

14. L. Trilling, "The Interaction of Inert Gas Molecules with a Continuous Elastic Solid," Surface Science 21, 1970.

15. Cooper, M. G., Mikic, B. B. and Yavanovich, M. M., "Thermal Contact Conductance," Journal of Heat and Mass Transfer 12, 1969. 


\section{ACKNOWLEDGMENTS}

We wish to thank the Core Performance Branch of the United States Atomic Energy Commission, Directorate of Licensing, for their support and guidance of this study. We also wish to thank Stan Goldsmith for his review and comments on the final report. 
APPENDIX A

DEFINITIONS AND UNITS FOR SYMBOLS USED IN EQUATIONS 
APPENDIX A

\section{DEFINITIONS AND UNITS FOR SYMBOLS USED IN EQUATIONS}

The metric units for various material properties and calculated parameters listed below were chosen to facilitate dimensional analysis and use of equations appearing in this report. For example, because the specific heat capacities of gases are usually tabulated in cal $/ \mathrm{g}-{ }^{\circ} \mathrm{C}$, and because the ratio of gas conductivity to specific heat capacity appears in the equations for temperature jump distance, gas conductivities, $K_{j}$, are in cal $/ \mathrm{sec}-\mathrm{cm}-{ }^{\circ} \mathrm{C}$. On the other hand, the mean solid-solid conductivity, $K_{m}$, appears in the equation for $h_{\text {solid }}$ as

$$
h_{\text {sol id }}\left(W / c^{2}-{ }^{\circ} C\right)=K_{m}\left(\frac{P_{a}}{H}\right)^{n} F(c m)^{-1}
$$

so that for $\mathrm{K}_{\mathrm{m}}$, the least cumbersome units are $\mathrm{W} / \mathrm{cm}-{ }^{\circ} \mathrm{C}$.

\begin{tabular}{|c|c|c|}
\hline Symbol & Meaning & Units \\
\hline$a_{i}$ & $\begin{array}{l}\text { The thermal accommodation coefficient } \\
\text { of the } i \text { th gas in a mixture }\end{array}$ & Dimensionless \\
\hline$a_{\operatorname{mix}}$ & $\begin{array}{l}\text { The accommodation coefficient for a } \\
\text { gas mixture as a whole }\end{array}$ & Dimensionless \\
\hline$c_{p}, c_{v}$ & $\begin{array}{l}\text { The specific heat capacities of a gas } \\
\text { at constant pressure and volume, } \\
\text { respectively }\end{array}$ & $\mathrm{cal} / \mathrm{g}-{ }^{\circ} \mathrm{C}$ \\
\hline$d$ & $\begin{array}{l}\text { The physical fuel-clad or solid-solid } \\
\text { gap dimension }\end{array}$ & $\mathrm{cm}$ \\
\hline$d_{\text {eff. }}$ & $\begin{array}{l}\text { The effective solid-solid separation } \\
\text { for solids in contact, due to their } \\
\text { roughness }\end{array}$ & $\mathrm{cm}$ \\
\hline$f_{i}$ & $\begin{array}{l}\text { The mole fraction of the } i^{\text {th }} \text { component } \\
\text { in a gas mixture }\end{array}$ & Dimensionless \\
\hline
\end{tabular}


$g_{1}, g_{2}$

$h_{\text {gas }}$

$h_{\text {solid }}$

hotal

$\mathrm{H}$

$\mathrm{K}_{\mathbf{j}}$

$K_{\text {mix }}\left(K_{\text {ga s }}\right)$

$k_{1}, k_{2}$

$K_{m}$

$L_{1}, L_{2}$

$M_{i}$

P

$P_{a}$

$\operatorname{Pr}$

$\mathrm{R}$

$R_{1}, R_{2}$

$\mathrm{s}_{1}, \mathrm{~s}_{2}$
The temperature jump distance at the fuel and cladding, respectively

The conductance per unit area through the interfacial gas

The conductance per unit area through points of solid-solid contact

Total conductance per unit area

The Meyer Hardness of the softer material in contact

The conductivity of the $i^{\text {th }}$ component in a gas mixture

The conductivity of a gas mixture (or pure gas) as a whole

Thermal conductivities of fuel and clad materials, respectively, evaluated at $T_{1}$ and $T_{2}$

The mean solid-solid conductivity, given by $2 K_{1} K_{2} /\left(K_{1}+K_{2}\right)$

The distance between peak heights on fuel and clad materials, respectively

The molecular weight of the $i^{\text {th }}$ gas in a mixture

The pressure of the interfacial gas

The apparent interfacial pressure

The Prandtl number for a gas (defined as $C_{p} u / K$ )

The gas constant. $\left(8.317 \times 10^{7}\right)$

The arithmetic mean roughnesses of fuel and clad, respectively

The standard deviations of peak heights of fuel and clad $\mathrm{cm}$

$\mathrm{W} / \mathrm{cm}^{2}-{ }^{\circ} \mathrm{C}$

$\mathrm{W} / \mathrm{cm}^{2}-{ }^{\circ} \mathrm{C}$

$\mathrm{W} / \mathrm{cm}^{2}-{ }^{\circ} \mathrm{C}$

$\mathrm{kgf} / \mathrm{cm}^{2}$

cal $/ \mathrm{sec}-\mathrm{cm}-{ }^{\circ} \mathrm{C}$

$\mathrm{cal} / \mathrm{sec}-\mathrm{cm}-{ }^{\circ} \mathrm{C}$

$\mathrm{W} / \mathrm{cm}-{ }^{\circ} \mathrm{C}$

$\mathrm{W} / \mathrm{cm}-{ }^{\circ} \mathrm{C}$

$\mathrm{cm}$

$\mathrm{g} / \mathrm{mole}$

dyne $/ \mathrm{cm}^{2}$

$\mathrm{kgf} / \mathrm{cm}^{2}$

Dimensionless

ergs $/ \mathrm{mole}-{ }^{\circ} \mathrm{C}$

$\mathrm{cm}$

$\mathrm{cm}$ 
Symbol

$\mathrm{T}_{1}, \mathrm{~T}_{2}$

$T_{\text {gas }}$

$u_{i}$

$u_{\operatorname{mix}}$

$\Delta X$
Meaning

The surface temperatures of fuel and clad materials

The average temperature of the interfacial gas

The viscosity of the $i^{\text {th }}$ component in a gas mixture

The viscosity of a gas mixture as a whole

The total effective width of solidsolid separation, such that

$h_{\text {gas }}=K_{\text {mix }} / \Delta x$
Units

${ }^{\circ} \mathrm{C}$

$0_{K}$

$\mathrm{g} / \mathrm{cm}-\mathrm{sec}$

$\mathrm{g} / \mathrm{cm}-\mathrm{sec}$

$\mathrm{cm}$ 
APPENDIX B

DERIVATION OF STANDARDIZED EQUATIONS

FOR TEMPERATURE JUMP DISTANCE 
DERIVATION OF STANDARDIZED EQUATIONS FOR TEMPERATURE JUMP DISTANCE

1. NOTES ON CALCULATION OF $\mathrm{K}_{\text {gas }}, \mathrm{K}_{\text {mix }}$, "a $i$ " and "a mix-

The calculation of gas conductivity, $\mathrm{K}_{\text {gas }}$, is performed according to Chapman-Enskog theory as recommended in Reference 9.

$$
K_{\text {gas }}=\frac{1.989 \times 10^{-4}}{\sigma_{\text {gas }}^{2} \Omega(z)} \sqrt{\frac{T_{\text {gas }}}{M}}
$$

where

$$
z=e_{\text {gas }}{ }^{\top} \text { gas } / k
$$

with

$$
k=\text { Boltzman's constant }
$$

$$
\text { e gas Leonard-Jones potential for the gas }
$$

and

$$
\sigma_{\text {gas }}=\text { an interaction distance characteristic of the gas }
$$

Values for $\sigma_{\text {gas }}, e_{\text {gas }} / k$, and $\Omega(z)$ are tabulated in Reference 9.

The conductivity of a mixture of gases, $k_{m i x}$, is calculated by weighting and adding the conductivities of the components:

$$
k_{\text {mix }}=\sum_{i}\left(f_{i} k_{i} / \sum_{j} f_{j} \phi_{i j}\right)
$$

The weighting function $\phi_{i j}$ is defined as

$$
\phi_{i j}=\frac{1}{\sqrt{8}}\left(1+\frac{M_{i}}{M_{j}}\right)^{-1 / 2}\left[1+\left(\frac{u_{i}}{u_{j}}\right)^{1 / 2}\left(\frac{M_{j}}{M_{i}}\right)^{1 / 4}\right]^{2}
$$

where the $u_{i}$ are the viscosities of the components.

It is worthwhile to note that the $u_{i}$ are proportional to the $k_{i}$ for monatomic gases. (The derivation of the correct proportionality constant is, in fact, a major accomplishment of the Chapman-Enskog theory.) The relation is 


$$
u_{i}=0.1343 \mathrm{~K}_{i} \mathrm{M}_{i}
$$

The calculations of the accommodation coefficient "a" used in this report are based on recent measurements by $U 11$ man, et al. ${ }^{(8)}$ of the accommodation coefficients of helium and xenon on $\mathrm{UO}_{2}$ and on stainless steel. Their data span a temperature range from 500 to $1000^{\circ} \mathrm{K}$, and suggest equations of the form:

$$
\begin{aligned}
& a_{H e}=0.425-2.3 \times 10^{-4} T_{i} \quad i=1,2 \\
& a_{X e}=0.749-2.5 \times 10^{-4} T_{i}
\end{aligned}
$$

These equations can be compared with a compilation of data listed by Trilling ${ }^{(14)}$ for helium, neon, argon, krypton and xenon on clean tungsten wire, for temperature up to $500^{\circ} \mathrm{K}$. U11man's data for $a_{x e}$ in the overlapping temperature region agrees quite well with Trilling's compilation, but Uliman's data for $\mathrm{a}_{\mathrm{He}}$ is one order of magnitude greater than comparable data from Trilling's sources. This may be due to difference in surface condition between clean tungsten wire and the rough, uncleaned surfaces deliberately used by Ullman. Because the latter surfaces are more typical, and because Ullman's $a_{H e}$ leads to larger (more conservative) estimates of temperature jump distance, we prefer to use Ullman's data until the discrepancy is resolved.

We calculated $a_{\operatorname{mix}}$ (for the Kennard equation) and $a_{i}$ for gases other than helium and xenon by linear interpolation between $a_{H e}$ and $a_{X e}$ based on molecular weight. The effective molecular weight of a gas mixture was taken to be

$$
\sum_{i} f_{i} M_{i} \text {. }
$$

At least for pure argon and krypton, this procedure is borne out by qualitative agreement with clean-wire data in Trilling's compilation.

\section{THE KENNARD EQUATION}

Kennard defines the accommodation coefficient as the ratio of the net average energy transfer from the gas molecules to a surface compared to 
that which would occur if impinging gas molecules came into thermal equilibrium with the surface. He then proceeds to derive the temperature jump distance in a straightforward way using classical mechanics. His final equation can be reduced for a pure gas to

$$
g=\left(\frac{2-a}{a}\right)\left(\frac{1}{T+C_{p} / C_{v}}\right)\left(\frac{K_{g a s}}{C_{v} P}\right)\left(\frac{2 \pi R T_{\text {gas }}}{M}\right)^{1 / 2}
$$

Note that $C_{v}=(3 / 2)(R / M)$ for a pure monatomic gas so that the equation can be written

$$
g=\left(\frac{2-a}{a}\right)\left(\frac{1}{1+C_{p} / C_{v}}\right)\left(\frac{K_{\text {gas }}}{P}\right)\left(\frac{4 \pi T_{\text {gas }}}{3 C_{v}}\right)^{1 / 2} \times 4.188 \times 10^{7}
$$

Now $C_{v}=\sum_{i} f_{i} c_{v_{i}}$

for monatomic gases, as a consequence of equipartition of energy. Hence, the term. under the radical can be written

$\frac{4 \pi T_{\text {gas }}}{3 \sum f_{i} C_{v_{i}} \times 4.188 \times 10^{7}}=\frac{8 \pi T_{\text {gas }}}{9 R \sum f_{i} / M_{i} \times 4.188 \times 10^{7}}=3.358 \times 10^{-8} \frac{T_{\text {gas }}}{\sum f_{i} / M_{i}}$

Then for a mixture of gases,

$$
g=\left(\frac{2-a_{\text {mix }}}{a_{\text {mix }}}\right)\left(\frac{1}{1+C_{p} / C_{v}}\right)\left(\frac{K_{\text {gas }} \sqrt{T_{\text {gas }}}}{p}\right)\left(\frac{1}{\sum f_{i} / M_{i}}\right)^{1 / 2} \times 7675 .
$$

Since the ration of heat capacities for monatomic gases is 1.667 , the equation can be reduced yet more to form

$$
g=\left(\frac{2-a_{\text {mix }}}{a_{\operatorname{mix}}}\right)\left(\frac{k_{\text {gas }} \sqrt{T_{\text {gas }}}}{P}\right)\left(\frac{1}{\sum f_{i} / M_{i}}\right)^{1 / 2} \times 2878 .
$$

and 
for pure gases.

$$
g=2878 \cdot\left(\frac{2-a}{a}\right)\left(\frac{K_{g a s} \sqrt{T_{\text {gas }}}}{P}\right) \sqrt{M}
$$

\section{THE GAPCON EQUATION}

The equations involved in the calculation for temperature jump distance in GAPCON-THERMAL-1 can be collated from the listing to form

$$
\left(g_{1}+g_{2}\right)=5.448\left(\frac{u_{\text {mix }}}{p}\right)\left(\frac{T_{\text {gas }}}{\sum f_{i} M_{i}}\right)^{1 / 2}
$$

with $P$ in psi.

Assuming $g_{1}=g_{2}=g$, and putting $P$ in dynes $/ \mathrm{cm}^{2}$, the equation becomes

$$
g=1.87 \times 10^{5}\left(\frac{u_{\operatorname{mix}}}{P}\right)\left(\frac{T_{\text {gas }}}{\sum f_{i}^{M_{i}}}\right)^{1 / 2}
$$

At first this does not appear to be of the same form as the Kennard equation, but recall from the notes above that $u_{i}=0.1343 K_{i} M_{i}$. Now $a$ similar form for $u_{\operatorname{mix}}$ exists as for $k_{\operatorname{mix}}(9)$ i.e.,

$$
u_{\operatorname{mix}}=\sum_{i} f_{i} u_{i} / \sum_{j} \phi_{i j} f_{j}
$$

Substituting for the $u_{i}$ in the above and multiplying and dividing by $k_{m i x}$ in the above one has that

$$
u_{\operatorname{mix}}=\left[\frac{\sum_{i} f_{i} K_{i} M_{i} / \sum_{j} \phi_{i j} f_{j}}{\sum_{i} f_{i} K_{i} / \sum_{j} \phi_{i j} f_{j}}\right] K_{\operatorname{mix}}
$$

So for mixed gases 


$$
g=25220 .\left(\frac{K_{\text {mix }} \sqrt{T_{\text {gas }}}}{P}\right)\left[\frac{\sum f_{i} K_{i} M_{i} / \sum_{j} \phi_{i j} f_{j}}{\sum f_{i} K_{i} / \sum_{j} \phi_{i j} f_{j}}\right] \sqrt{\frac{1}{\sum^{f_{i} M_{i}}}}
$$

For pure gases, this reduces to a form very similar to the corresponding Kennard equation:

$$
g=25220 . \frac{K_{\text {gas }} \sqrt{T_{\text {gas }}}}{P} \sqrt{M}
$$

\section{THE LLOYD EQUATION}

A fresh outlook on the whole problem of temperature jump distance is presented by Lloyd. He developed a model from detailed consideration of the particle fluxes of each species of gas in a mixture, and the heat flux they carry from surface to gas based on $P_{j}$ transport theory. His final equation can be expressed as

$$
g=\frac{K_{\text {mix }}}{1.942 \sum_{i}^{j} \frac{a_{i} P_{i}}{\sqrt{M_{i} T_{\text {gas }}^{\prime}}}}
$$

where $P_{i}$ are partial pressures in Torr. and $K_{\text {gas }}$ is in Watt $/ \mathrm{cm}-{ }^{\circ} \mathrm{C}$. Note $T_{\text {gas }}^{\prime}$ is the gas temperature just ahead of temperature jump rather than the average gas temperature (the distinction is not preserved in the comparative calculations performed in parts I.C and I.D of this paper).

Recognizing $P_{i}=f_{j} P$ and changing pressure units to dynes $/ \mathrm{cm}^{2}$ and temperature units to $\mathrm{cal} / \mathrm{sec}-\mathrm{cm}-{ }^{\circ} \mathrm{C}$, the equation becomes 


$$
g=2875 \cdot\left(\frac{k_{\text {mix }} \sqrt{T_{\text {gas }}}}{P}\right)\left(\frac{1 .}{\sum f_{i^{a}{ }_{i} / \sqrt{M_{i}}}}\right)
$$

This reduces to the familiar form for pure gases:

$$
g=2875 \cdot\left(\frac{K_{\text {gas }} \sqrt{T_{\text {gas }}}}{P}\right)\left(\frac{\sqrt{M}}{a}\right)
$$

Note: The equation for $K_{\text {gas }}$ applies without correction only for temperatures greater than 10 times the critical temperature and pressures less than 30 to 100 times the critical pressure. Reference 9 tabulates the critical values, and referral to the reduced thermal conductivity curves in the same reference will assure one that for all practical cases in power-reactor application the equation given for Kgas does apply. 
APPENDIX C

DERIVATION OF STANDARDIZED EQUATIONS FOR $h_{\text {solid }}$ 
APPENDIX C

DERIVATION OF STANDARDIZED EQUATIONS;

$\underline{F O R h_{\text {SOl id }}}$

\section{THE CETINKALE-F ISHENDEN MODEL ${ }^{(5)}$}

This model assumes a fixed number $N$ of equally spaced contact points per unit area. Associated with each contact spot is a fictitious cylinder of radius $r_{e}$. The total cross-sectional area of $N$ of these cylinders comprise a unit area, such that $\mathrm{N} \pi r_{e}{ }^{2}=1$. The true radius of each contact spot, $r$, is assumed to be related to $r_{e}$ by the formula,

$$
r^{2}=r_{e}^{2}\left(P_{a} / H\right)
$$

That is, as the apparent contact pressure $P_{a}$ increases, the true contact pressure [which is $\left(r_{e}{ }^{2} / r^{2}\right) P_{a}$ ] is never greater than the Meyer hardness of the softer material, $H$. The radius $r$ increases for each contact point to maintain this condition. Cetinkale and Fishenden derived the resistance to heat flow consequent from constricting the lines of heat flow through a contact point (as opposed to unrestricted flow through the equivalent cylinder). This so-called constriction resistance they found to be

$$
\begin{aligned}
R_{\text {constr. }} & =\frac{r_{e}^{2} \tan ^{-1}\left(r_{e}{ }^{2} / r^{2}-1\right)}{K_{m} r} \\
& =\frac{r_{e}{ }^{2}(\pi / 2)}{K_{m} r}
\end{aligned}
$$

since $r_{e}^{2} \gg r^{2}$

Taking the reciprocal $1 / R_{\text {constr. }}$ to be $h_{\text {solid, }}$, and using the relationship between the contact spot and equivalent cylinder radi $i$, we have the Cetinkale-Fishenden equation for $h_{\text {solid }}$ : 


$$
h_{\text {solid }}=(2 / \pi)\left(K_{m} / r_{e}\right)\left(P_{a} / H\right)^{1 / 2}
$$

From measurements of $h_{\text {solid }}, r_{e}$ could be deduced, and the empirical relation

$$
r_{e}=0.0048\left(P_{a} / H\right)^{-5 / 6}\left(L_{1}+L_{2}\right)
$$

was found by Cetinkale and Fishenden to correlate their measurements.

Combining this with their basic $h_{\text {solid }}$ equation yields their final model for $h_{\text {sol id }}$ :

$$
h_{\text {sol id }}=\frac{132.6 K_{m}}{\left(L_{1}+L_{2}\right)}\left(\frac{P_{a}}{H}\right)^{4 / 3}
$$

2. THE RAPIER-JONES MODEL (7)

Rapier et al., developed their model along the same lines as

Cetinkale and Fishenden, the difference being that they estimated $r_{e}$ from the wavelength of the surface with larger wavelength. The wavelength was assumed uniform in azimuthal direction, such that

$$
r_{e}=(\pi / 2) L_{l} \text {. }
$$

Combining this with Cetinkale-Fishenden's basic $h_{\text {solid }}$ equation yields as modified model for $h_{\text {solid }}$ :

$$
h_{\text {solid }}=\left(K_{m} / L_{1}\right)\left(P_{a} / H\right)^{1 / 2}
$$

3. THE ROSS-STOUTE MODEL (2)

Ross and Stoute attempted to correlate their measurements of $h_{\text {solid }}$ for $\mathrm{UO}_{2}$ and zirconium pairs by using just one measured surface parameter, i.e., the mean surface roughnesses, $R_{1}$ and $R_{2}$. They combined the two roughnesses as 


$$
R=\left(\frac{R_{1}^{2}+R_{2}^{2}}{2}\right)^{1 / 2}
$$

and then took the square root of $R$ times a free parameter, $A_{0}$, to be the correlating parameter. This procedure shifts the correlation of their data from the measured $R$ to the chosen $A_{0}$, and would not be very meaningful were it not for the fact that "best choices" for $A_{0}$ only ranged from about 0.5 to 1.0 for their data.

Their equation for $h_{\text {solid }}$ is:

$$
h_{\text {solid }}=\frac{1.189 K_{m}}{\left(R_{1}^{2}+R_{2}^{2}\right)^{1 / 4}}\left(\frac{P_{a}}{H}\right) \text { for } A_{0}=1.0
$$

\section{FENECH-ROHSENOW}

Use of this model depends on determining the number of contact spots per unit area, $n$, by a graphical method. The expression for $h$ in vacuum environment is

$$
h_{\text {solid }}=\left(\frac{E^{2}}{1-E^{2}}\right)\left[\frac{1}{\left(4.26 R_{1}+\frac{E}{\sqrt{n}}\right) k_{2}+\left(4.26 R_{2}+\frac{E}{\sqrt{n}}\right) k_{1}}\right]
$$

where $R_{7}, R_{2}$ are mean heights of the surfaces

$$
\mathrm{k}_{1}, \mathrm{~K}_{2} \text { are the conductivities }
$$

and $E^{2}=\frac{\text { actual contact area }}{\text { apparent contact area. }}$

If one makes the following approximations

$$
\begin{aligned}
& E^{2}=P_{a} / H \\
& E^{2} \quad \ll<1 \\
& n=\frac{\Pi}{4 L_{1}^{2}}, \quad \sqrt{n} \gg>1 \\
& R_{1}=R_{2}=\left(R_{1}+R_{2}\right) / 2
\end{aligned}
$$


Then the model reduces to

$$
h=\frac{4.26 K_{1} K_{2} E^{2}}{\left(4.26 R+\frac{2 L}{\pi}-1 E^{E}\right)\left(K_{1}+K_{2}\right)}=\left[\frac{1.89 K_{m}}{1.89\left(R_{1}+R_{2}\right)+\left(P_{a} / H\right)^{1 / 2} L_{1}}\right]\left(\frac{P_{a}}{H}\right)
$$

\section{THE MIKIC-TODREAS MODEL (12)}

The original model for contact conductance by Mikic sought to account for the fact that the conductance should be a function of the roughnesses (which somehow determine an effective roughness for the plane-on peaks model) and the slope of the asperities on the more "peaked" surface (which controls the number of actual contact spots per unit area).

The original model is

$$
h_{\text {solid }}=\frac{1.45 k_{m}(\overline{\tan \theta})_{c}}{S}\left(\frac{P_{a}}{H}\right)^{n}
$$

where $(\overline{\tan \theta})_{C}$ is the average slope of the asperities on the controlling surface, the one for which $\overline{\tan \theta}$ is larger. The exponent $n$ is 0.5 at low pressure, reflecting the idea that a fixed number of higher peaks per unit area control the conductance. At higher pressure, $n$ approaches 1.0 , as the number of contact spots begins to increase proportionately to increasing pressure. Todreas concluded that, for $\mathrm{UO}_{2}$-zirconium interfaces, the transition pressure is around 1,000 psia.

The model may be put in terms of $R_{j}$ and $L_{i}$ by assuming*

$$
\begin{aligned}
\overline{\tan \theta_{i}} & =2 R_{i} / L_{i} \\
S & =\left(S_{1}^{2}+S_{2}^{2}\right)^{1 / 2} \\
S_{i} & =\sqrt{\frac{\pi}{2}} R_{i}
\end{aligned}
$$

* See Appendix C of Mikic's paper (15) for explanation of these assumptions. Basically a model involving equally spaced identically shaped, peaks on both surfaces is substituted for the real situation. The distribution of peak heights is assumed to be normal. 
The model then becomes

$$
h_{\text {solid }}=2.314 \mathrm{Km}\left[\frac{\mathrm{R}_{\mathrm{c}}}{\left(\mathrm{R}_{1}{ }^{2}+\mathrm{R}_{2}{ }^{2}\right)^{1 / 2} \mathrm{~L}_{\mathrm{c}}}\right]\left(\frac{\mathrm{P}_{\mathrm{a}}}{\mathrm{H}}\right)^{\mathrm{n}}
$$

6. THE SHLYKOV CORRELATION

The solid-solid conductance portion of the Shlykov correlation is given by

$$
h_{\text {solid }}=118.9 \mathrm{~K}_{\mathrm{m}}\left(\frac{\mathrm{QP}_{\mathrm{a}}}{\mathrm{H}}\right)^{0.86}
$$

where $Q=1.0$ for $\left(R_{1}+R_{2}\right)>0.003 \mathrm{~cm}$

$$
\begin{aligned}
& =\left(\frac{0.0030}{R_{1}+R_{2}}\right)^{1 / 3} \text { for } 0.001<\left(R_{1}+R_{2}\right)<0.003 \mathrm{~cm} \\
& =\frac{0.0015}{R_{1}+R_{2}} \text { for }\left(R_{1}+R_{2}\right)<0.001 \mathrm{~cm} .
\end{aligned}
$$

\section{THE DEAN MODEL}

The solid-solid conductance portion of the Dean model is presented as

$$
140 K_{m}\left(\frac{P_{a}}{H}\right)\left(\frac{1}{L_{1} L_{2}}\right)^{1 / 2}=h_{\text {sol id }}
$$

where, for $h_{\text {solid }}$ in Btu/hr-ft ${ }^{2}-{ }^{\circ} F, K_{m}$ is $B t u / h r-f t-{ }^{\circ} F, L_{1}, L_{2}$ are in inches.

Changing $\mathrm{K}_{\mathrm{m}}$ to $\mathrm{W} / \mathrm{cm}-{ }^{\circ} \mathrm{C}$ and $\mathrm{L}_{1}, \mathrm{~L}_{2}$ to $\mathrm{cm}$ requires the constant to change to 11.67 for $h_{\text {solid }}$ in $W / \mathrm{cm}^{2}-{ }^{\circ} \mathrm{C}$.

The derivation of this model is similar to that of Rapier's, except that the wavelengths of both surfaces are assumed to affect the number of contact points per unit area, in an equal way. 


\section{DISTRIBUTION}

No. of

Copies

\section{OFFSITE}

1 ERDA Chicago Patent Group

9800 S. Cass Avenue

Argonne, Illinois 60439

A. A. Churm

230 ERDA Technical Information Center

\section{ONSITE}

1 ERDA Richland Operations

Office

Program Division

B. J. Melton

14 Battel le-Northwest

C. R. Hann

D. D. Lanning (10)

Technical Information Files (2)

Technical Publications 